\title{
Changing seasonality of the Baltic Sea
}

\author{
Mati Kahru ${ }^{1}$, Ragnar Elmgren ${ }^{2}$, and Oleg P. Savchuk ${ }^{3}$ \\ ${ }^{1}$ Scripps Institution of Oceanography, University of California San Diego, La Jolla, California \\ ${ }^{2}$ Department of Ecology, Environment and Plant Sciences, Stockholm University, Stockholm, Sweden \\ ${ }^{3}$ Baltic Nest Institute, Stockholm University, Stockholm, Sweden
}

Correspondence to: Mati Kahru (mkahru@ucsd.edu)

Received: 30 October 2015 - Published in Biogeosciences Discuss.: 25 November 2015

Revised: 25 January 2016 - Accepted: 29 January 2016 - Published: 23 February 2016

\begin{abstract}
Changes in the phenology of physical and ecological variables associated with climate change are likely to have significant effect on many aspects of the Baltic ecosystem. We apply a set of phenological indicators to multiple environmental variables measured by satellite sensors for 17-36 years to detect possible changes in the seasonality in the Baltic Sea environment. We detect significant temporal changes, such as earlier start of the summer season and prolongation of the productive season, in several variables ranging from basic physical drivers to ecological status indicators. While increasing trends in the absolute values of variables like sea-surface temperature (SST), diffuse attenuation of light (Ked490) and satellite-detected chlorophyll concentration (CHL) are detectable, the corresponding changes in their seasonal cycles are more dramatic. For example, the cumulative sum of $30000 \mathrm{~W} \mathrm{~m}^{-2}$ of surface incoming shortwave irradiance (SIS) was reached 23 days earlier in 2014 compared to the beginning of the time series in 1983 . The period of the year with SST of at least $17^{\circ} \mathrm{C}$ has almost doubled (from 29 days in 1982 to 56 days in 2014), and the period with Ked490 over $0.4 \mathrm{~m}^{-1}$ has increased from about 60 days in 1998 to 240 days in 2013 - i.e., quadrupled. The period with satellite-estimated CHL of at least $3 \mathrm{mg} \mathrm{m}^{-3}$ has doubled from approximately 110 days in 1998 to 220 days in 2013. While the timing of both the phytoplankton spring and summer blooms have advanced, the annual CHL maximum that in the 1980s corresponded to the spring diatom bloom in May has now shifted to the summer cyanobacteria bloom in July.
\end{abstract}

\section{Introduction}

Estuarine areas world-wide are experiencing rapid changes due to anthropogenic pressures of both local and global nature (Cloern et al., 2016). The ecosystem of the brackish Baltic Sea has been under anthropogenic stress for many decades (Elmgren, 1989, 2001). Both direct effects, such as input of nutrients and various pollutants, and indirect effects through climate change are important. Time series of environmental variables show variability at multiple scales but separating the effects of natural climate variability from the effects of anthropogenic climate change is difficult. We apply a set of phenological indicators to multiple environmental variables, mostly from satellite sensors, to detect changes in the environment. It appears that phenological indicators are very sensitive in detecting environmental change. We show significant changes in the seasonality of both the physical drivers and in ecological indicators of the Baltic Sea. Increasing trends are detectable in the absolute values of sea-surface temperature (SST) and water turbidity, but changes in their seasonal cycles are more clear-cut. The seasonality of a number of abiotic and biotic variables for which data are available has changed drastically during the last few decades. These changes are likely to have major effects on many aspects of the Baltic Sea ecosystem. 
Table 1. Satellite-derived data sets used here to produce phenological indicators.

\begin{tabular}{|c|c|c|c|}
\hline Variable & Acronym & Units & Sample sources \\
\hline Surface incoming shortwave irradiance & SIS & $\mathrm{W} \mathrm{m}^{-2}$ & $\begin{array}{l}\text { EUMETSAT, NOAA, NASA } \\
\text { Doi:10.5676/EUM } \\
\text { SAF_CM/SARAH/V001 }\end{array}$ \\
\hline Sea-surface temperature & SST & ${ }^{\circ} \mathrm{C}$ & $\begin{array}{l}\text { NOAA, NASA, GHRSST } \\
\text { http://www.nodc.noaa.gov/ } \\
\text { SatelliteData/pathfinder4km/ } \\
\text { http://ghrsst.jpl.nasa.gov }\end{array}$ \\
\hline Near-surface wind & WSP, directional wind & $\mathrm{ms}^{-1}$ & $\begin{array}{l}\text { NASA } \\
\text { http://podaac.jpl.nasa.gov/datasetlist? } \\
\text { ids=Collections\&values=CCMP; } \\
\text { EUMETSAT Ocean and Sea Ice SAF, } \\
\text { http://www.osi-saf.org/ }\end{array}$ \\
\hline Coefficient of diffuse light attenuation & KED & $\mathrm{m}^{-1}$ & $\begin{array}{l}\text { ESA } \\
\text { http://www.esa-oceancolour-cci.org/ }\end{array}$ \\
\hline Near-surface chlorophyll $a$ concentration & $\mathrm{CHL}$ & $\mathrm{mg} \mathrm{m}^{-3}$ & $\begin{array}{l}\text { ESA } \\
\text { http://www.esa-oceancolour-cci.org/ }\end{array}$ \\
\hline Fraction of cyanobacteria accumulations & FCA & unitless & Kahru and Elmgren (2014) \\
\hline
\end{tabular}

\section{Methods and data sets}

\subsection{Data sets}

The data sets used in this analysis and their sources are shown in Table 1. Surface incoming shortwave irradiance (SIS) data were produced from geostationary Meteosat satellites (Mueller et al., 2009, Müller et al., 2015) using a climate version of the Heliosat algorithm (Cano et al., 1986, Beyer et al., 1996) and obtained from the Satellite Application Facility on Climate Monitoring (CM SAF, http://www.cmsaf.eu/EN/ Products/AvailableProducts/Dataset/Dataset_node.html).

SST data produced by NOAA and NASA were obtained from http://www.nodc.noaa.gov/SatelliteData/ pathfinder4km (Casey et al., 2010).

Near-surface wind data were assembled from two sources. Data for 1987-2011 are version 3.5a from the Cross-Calibrated Multi-Platform (CCMP) Ocean Surface Wind Components (Atlas et al., 2008), available from ftp://podaac-ftp.jpl.nasa.gov/allData/ccmp/L3.5a/. Data for 2013-2015 are from ASCAT, produced by the KNMI Scatterometer Team and available from the EUMETSAT Ocean and Sea Ice SAF (http://www.osi-saf.org/).

Satellite-detected coefficient of attenuation of diffuse downwelling light at $490 \mathrm{~nm}(\operatorname{Ked} 490)$ and near-surface chlorophyll concentration (CHL) are produced by the ESA Ocean Colour Climate Change Initiative project (Lavender et al., 2015) using satellite data archives of NASA's SeaWiFS and MODIS-Aqua sensors and ESA's MERIS sensor. Version 2.0 data sets were downloaded from ftp://oc-cci-data: ELaiWai8ae@oceancolour.org/. The Ked490 algorithm uses the Lee et al. (2005) semianalytic method. The CHL algo- rithm is based on an empirical ratio of remote sensing reflectance (O'Reilly et al., 1998).

Fraction of cyanobacteria accumulations (FCA, Kahru et al., 2007; Kahru and Elmgren, 2014) is a form of presenting the frequency of cyanobacteria accumulations that is normalized to the number of unobstructed satellite views of the sea surface. This normalization is needed as clouds often cover the sea surface and make it impossible to detect accumulations.

\subsection{Phenological and cumulative indicators}

For the analysis of changes in the annual cycle we use the following phenological indicators (Table 2):

1. Day of year when a threshold value is first reached $(\mathrm{DF}=$ "day first");

2. Day of year when a threshold value is last reached $(\mathrm{DL}=$ "day last");

3. Duration between the first and last reaching of a threshold value (DD = "day duration");

4. Day of year when the annual maximum occurs (DM = "day maximum") (e.g. Kahru et al., 2010);

5. Count of days above a threshold value ( $\mathrm{DC}=$ "day count").

These indicators can be applied to different satellitederived or in situ variables. Satellite versions of these indicators were spatially averaged over the area of interest e.g., the whole Baltic Sea or parts of it (Fig. 1). The nomenclature of indicators uses two characters showing the type of indicator (e.g., DF, DL, etc.), followed by the variable 
Table 2. Summary of proposed climate indicators.

\begin{tabular}{lll}
\hline Explanation & Type & Example variable groups \\
\hline First day of reaching a threshold & DF & DFSST, DFCHL, DFKED \\
Last day of reaching a threshold & DL & DLSST, DLCHL, DLKED \\
Duration of the period between DF and DL & DD & DFSST, DDCHL, DDKED \\
Count of days over the threshold & DC & DCSST, DCCHL, DCKED \\
Day of reaching the annual maximum & DM & DMSST, DMCHL, DMKED \\
First day of reaching a cumulative threshold & DFCUM & DFCUMSIS, DFCUMSST \\
Cumulative count of days above threshold & DCCUM & DCCUMSIS, DCCUMSST \\
\hline
\end{tabular}
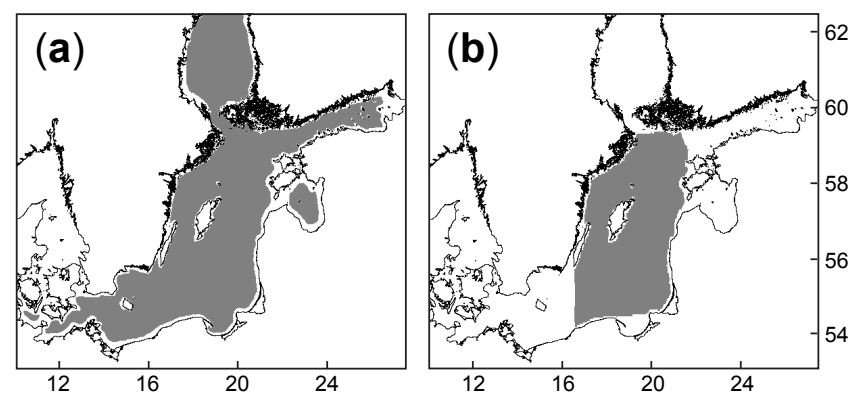

Figure 1. Maps of the study areas. (a) Baltic Sea area excluding shallow coastal areas and the Bothnian Bay (Kahru et al., 2007). (b) Central Baltic Sea including the following sub-basins: Northern Baltic Proper, Western and Eastern Gotland Basin and the Southeastern Baltic Proper. The shaded areas are used to calculate averages for, respectively, Baltic and central Baltic Sea.

type (e.g., SST for sea-surface temperature), and followed by the threshold value (e.g., 16 for $16^{\circ} \mathrm{C}$ of SST). For example, DFSST16 shows the first day of year when the spatially averaged SST reaches a threshold value of $16^{\circ} \mathrm{C}$; DLCHL3 shows the last day of year when the spatially averaged CHL reaches $3 \mathrm{mg} \mathrm{m}^{-3}$. An example of a cumulative indicator is DFCUMSIS500 - i.e., the day of year when the cumulative sum of daily SIS irradiance reaches $500 \mathrm{~W} \mathrm{~m}^{-2}$.

The existence of trends and their significance was evaluated with the nonparametric Sen slope (Sen, 1968) and the Mann-Kendall test using $95 \%$ significance level (Salmi et al., 2002). In parallel, $95 \%$ confidence limits of the least squares linear regression slope (as implemented in NMath numerical libraries, http://www.centerspace.net) were also used.

\section{Results}

\subsection{Surface incoming shortwave irradiance}

The radiation budget at the Earth's surface is a key variable affecting other variables such as surface temperature, primary production, etc. The incoming shortwave irradiance (SIS, $\mathrm{W} \mathrm{m}^{-2}$ ) shows highly regular annual cycles without obvious trends (Fig. 2). However, a cumulative phenological

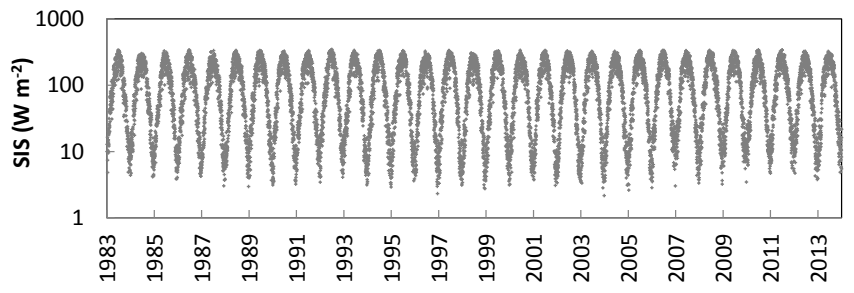

Figure 2. Time series of the daily surface incoming shortwave irradiance (SIS, $\mathrm{W} \mathrm{m}^{-2}$ ) derived from geostationary Meteosat sensors, averaged over the shaded area of the Baltic Sea shown in Fig. 1a.

indicator, DFCUMSIS (Table 2) - i.e., the cumulative sum of daily SIS - shows subtle but significant changes in its seasonality (Fig. 3a). It appears that the annual cycle of incoming shortwave energy has changed towards a decrease in the winter and increase during the spring and summer. Therefore the lower cumulative thresholds of total incoming irradiance are reached later in the season and the slope is positive. However, the higher cumulative thresholds of total incoming irradiance are reached earlier and the slope of the year day of reaching a threshold value against year is negative (Fig. 3a). The shift from later towards earlier cumulative thresholds occurs in spring, around year day 75 or approximately March 15 . The slope of the time of reaching a certain threshold value as a function of time (Fig. 3b) has a clear pattern. The slope is positive, indicating later cumulative totals in SIS early in the year, until about $1000 \mathrm{~W} \mathrm{~m}^{-2}$, but becomes negative later in the year, indicating earlier cumulative totals in late spring and summer. As a result of the observed trends in timing, the cumulative sum of $30000 \mathrm{~W} \mathrm{~m}^{-2}$ was reached approximately on day 237 in 1983 but on day 214 in 2014 - i.e., 23 days earlier. In contrast to this significant change in timing, no significant changes in the absolute daily values are evident in the time series.

\subsection{Sea-surface temperature}

As global time series of SST are available for several decades (Casey et al., 2010), SST is a good variable for phenological analysis. While SST itself is an important driver affecting the rates of biological processes, its indirect effects through its influence on stratification are probably more important. 
(a)

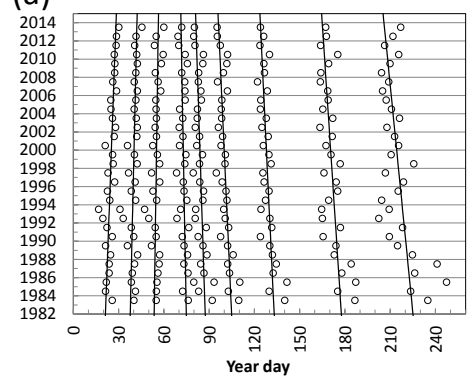

(b)

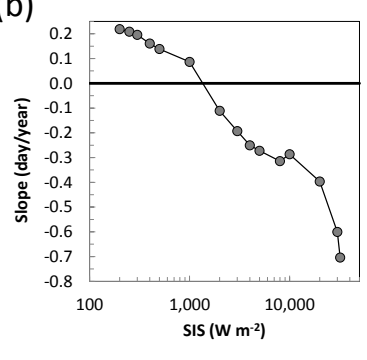

Figure 3. Changing seasonality in cumulative surface incoming shortwave irradiance (SIS, $\mathrm{W} \mathrm{m}^{-2}$ ) averaged over the area of the Baltic Sea indicated in Fig. 1a. (a) DFCUMSIS - i.e., day of year when the annual sum of daily mean SIS reaches the following thresholds: 200, 500, 1000, 2000, 3000, 5000, 10000,20000 and $30000 \mathrm{~W} \mathrm{~m}^{-2}$. For each threshold the circles show the day of the year and the line shows the respective linear regression. (b) Slopes of the linear regressions in panel (a).

Near-surface stratification suppresses vertical mixing in the water column and affects many ecological processes, such as the flux of nutrients to the surface layer or the accumulation of cyanobacteria near the water surface. As cyanobacteria growth in temperate environments is enhanced by higher temperatures and near-surface stratification, SST is an important environmental driver for these blooms (Paerl and Huisman, 2008). Cyanobacteria growth typically accelerates when SST exceeds $12^{\circ} \mathrm{C}$ and peaks above $17^{\circ} \mathrm{C}$ (Hense et al., 2013). We therefore estimated the start of the cyanobacterial growth season as the first day when the spatially averaged SST reached $12^{\circ} \mathrm{C}$ (DFSST12), the end of the growth season as the last day with SST of at least $12^{\circ} \mathrm{C}$ (DLSST12) and the duration of the growth season as the number of days between those dates (DDSST12=DLSST12 - DFSST12). Similarly, the "peak growth season" is parameterized by the respective indicators (DFSST17, DLSST17 and DDSST17) for a SST of $17^{\circ} \mathrm{C}$. Significant trends towards an earlier start and a later end of the growth season were detected for these timing indicators (Fig. 4).

It appears that while the springtime warming of the sea surface has become significantly earlier (i.e., the slope of DFSST vs. year is negative), particularly for colder temperatures, the time in summer when the higher temperatures are reached has not changed and the trend is not significant for any SST above $16^{\circ} \mathrm{C}$ (Fig. 5a). In contrast, the slope for DLSST is positive, indicating delay of the fall cooling, with the highest slopes for SSTs of 15 to $17^{\circ} \mathrm{C}$ (Fig. 5a). As a result of the earlier warming and later cooling, the period with SST above a certain threshold (DDSST) has changed quite dramatically, particularly for SST values of $\sim 15-16^{\circ} \mathrm{C}$ (Fig. 5b). The rate of change for DDSST16 has been almost a day per year $\left(0.98\right.$ day year $\left.^{-1}\right)$. As a result, the duration of the period with a mean SST of at least $16^{\circ} \mathrm{C}$ has increased from about 40 days in 1982 to about 72 days in 2014 - i.e.,

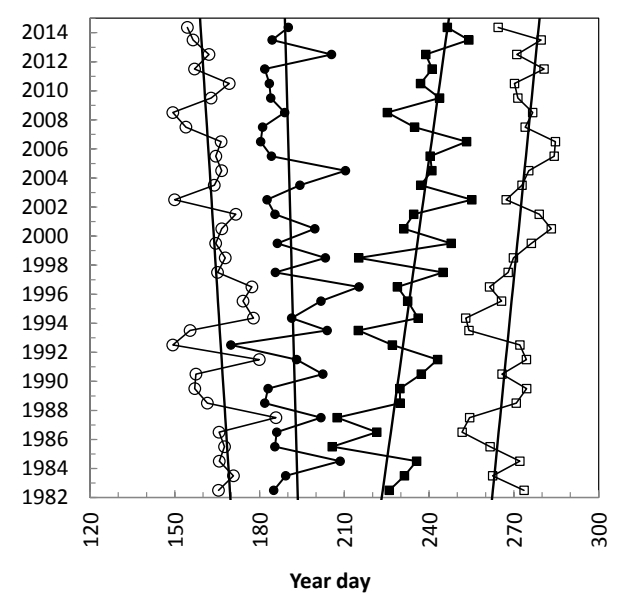

Figure 4. Changes in satellite-detected SST phenology in the Baltic Sea (area indicated in Fig. 1a). The symbols and regression lines are (left to right): first day when $12^{\circ} \mathrm{C}$ is reached (DFSST12, open circles), first day when $17^{\circ} \mathrm{C}$ is reached (DFSST17, filled circles), last day when $17^{\circ} \mathrm{C}$ is reached (DLSST17, filled squares), last day when $12{ }^{\circ} \mathrm{C}$ is reached (DLSST12, open squares).

by 32 days (Fig. 5b). Similarly, the duration of the period with SST of at least $17^{\circ} \mathrm{C}$ (DDSST17) has increased from 29 days in 1982 to about 56 days in 2014 - i.e., almost doubled. These are drastic changes in the phenology of an important driver of ecosystem processes. In contrast, the timing and the duration of the period with the highest SST $\left(\sim 22^{\circ} \mathrm{C}\right)$ has not changed significantly. It is important to note that while a significant increase in the mean summertime SST is evident in the Baltic Sea (Belkin, 2009), this increase is rather small compared to the annual range of SST, from about $0{ }^{\circ} \mathrm{C}$ in the winter to about $22^{\circ} \mathrm{C}$ in the summer. The phenology of the changes gives a more detailed and ecologically highly relevant picture that complements the general increase in mean SST.

\subsection{Wind}

Wind speed and direction are important variables that affect the biology of the Baltic surface waters. In a previous study (Kahru et al., 2007) we found a correlation between the location of the major cyanobacteria accumulations either in the southern or northern half of the Baltic and the strength of wind in the northeasterly direction. We therefore examined the mean annual cycle in the strength of winds in the northeastern direction (NE-ward winds) and the possible changes to it. The annual cycle of the NE-ward winds has a minimum in April and a subsequent increase after that (Fig. 6a). We examined whether the onset of the summer increase in NE-ward winds has changed. While the last 7 years (2008 to 2015) show a steady shift towards earlier start of the summer wind increase (Fig. 6b), the large interannual variability precludes establishing a long-term trend and the changes in the 
(a)

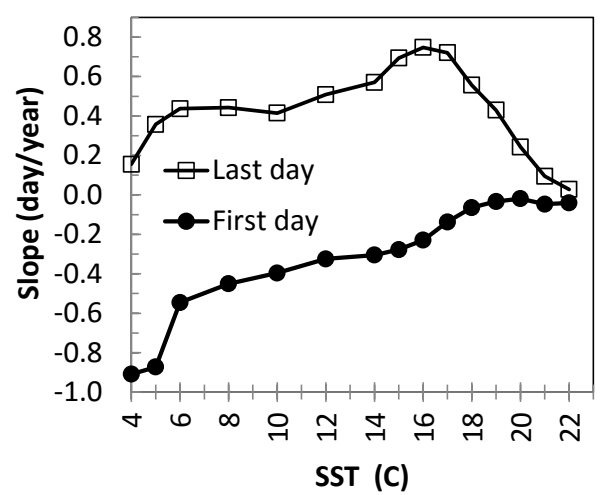

(b)

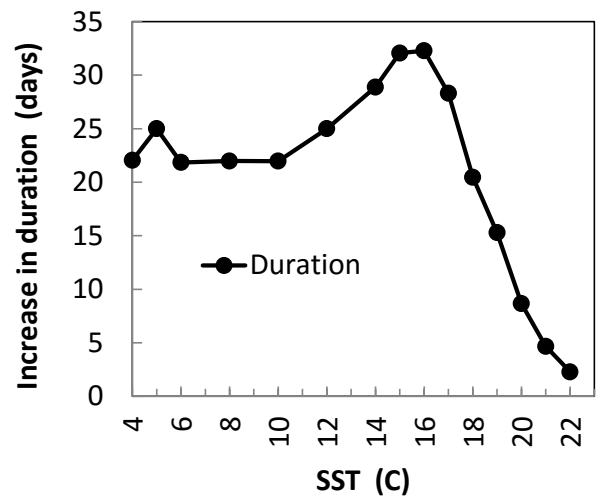

Figure 5. (a) Rate of change (day year ${ }^{-1}$ ) in the day of year when a certain SST level is first reached (DFSST, filled circles) and when a certain SST level is last reached in a season (DLSST, open squares) for the Baltic Sea (area indicated in Fig. 1a). (b) Increase in the duration of a period with SST above a certain level (DDSST) from 1982 to 2014.

starting time of the summer increase in NE-ward winds are not significant.

\subsection{Attenuation of light, Ked490}

The coefficient of downwelling light at $490 \mathrm{~nm}(\mathrm{Ked} 490)$ is a commonly used indicator of water transparency (e.g., Kratzer et al., 2003; Lee et al., 2005) that can be estimated from a satellite sensor. It reflects both light absorption - e.g., by colored dissolved organic matter (CDOM) and phytoplankton pigments - and scattering of light by particles. The timing of the increase in Ked490 has changed significantly during the time period with reliable satellite data (1997 to present). The summer period with high Ked490 corresponding to low water transparency has become earlier and persisted longer into the fall (Fig. 7). Significantly, these changes have been more pronounced for the higher values of Ked490 than for the lower values of Ked490. For example, using the regression lines in Fig. 7, we can estimate that from 1998 to 2013 the period with mean Ked490 over $0.1 \mathrm{~m}^{-1}$ has become longer by 35 days whereas over the same period the duration of the mean Ked490 over $0.4 \mathrm{~m}^{-1}$ has increased from about 60 days in (a)

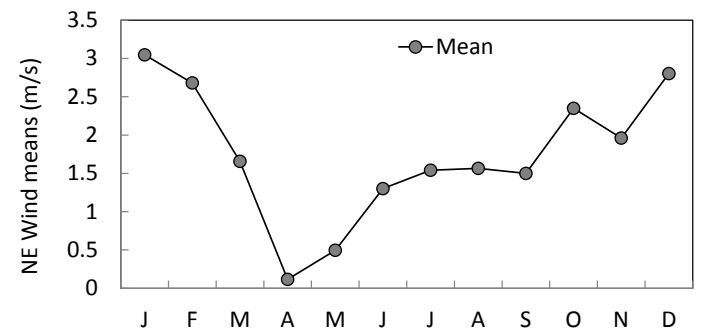

(b)

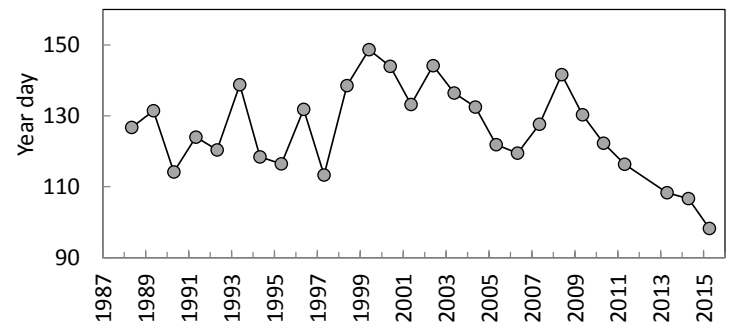

Figure 6. (a) Annual cycle in the mean monthly wind speed in the NE direction in the Baltic Sea (area indicated in Fig. 1a). (b) Day of the year when the 5-day mean wind in the NE direction exceeds $2 \mathrm{~m} \mathrm{~s}^{-1}$ for the first time after the April minimum.

1998 to 240 days in 2013 - i.e., has become longer by 180 days. However, the last 1-2 years seem to show a reversal of the trend.

\subsection{Near-surface chlorophyll $a$}

The satellite-derived surface concentration of $\mathrm{CHL}$ is an important measure of the amount of phytoplankton, but is known to have large errors in the Baltic Sea (Darecki and Stramski, 2004; Attila et al., 2013). This is due both to problems in the atmospheric correction procedures and in the separation of phytoplankton pigments from the CDOM. The standard CHL algorithm essentially measures total absorption of blue light by a mixture of phytoplankton pigments, non-algal particles and CDOM. The separation of these components is made difficult by the large and variable concentrations of CDOM that are typical of the Baltic Sea. While the satellite-derived CHL overestimates true near-surface CHL in the Baltic Sea due to the high concentration of CDOM (Darecki and Stramski, 2004), the phenology of CHL is still a meaningful indicator of the timing of phytoplankton blooms, as the early increase in turbidity is well correlated with phytoplankton spring bloom and the summer maximum in turbidity is correlated with the cyanobacteria blooms in the central Baltic Sea.

The time series of CHL in the central Baltic Sea (Fig. 8) shows the well-known annual cycle with maxima corresponding to the summer cyanobacteria and the spring diatom blooms. A statistically significant increasing trend can be detected in the 1998-2013 time series of mean CHL in central Baltic Sea (Fig. 8) with a slope of $0.067 \mathrm{mg} \mathrm{m}^{-3}$ year $^{-1}$. However, it is not clear how much of the increase is truly due to an increase in phytoplankton vs. increases in CDOM and 


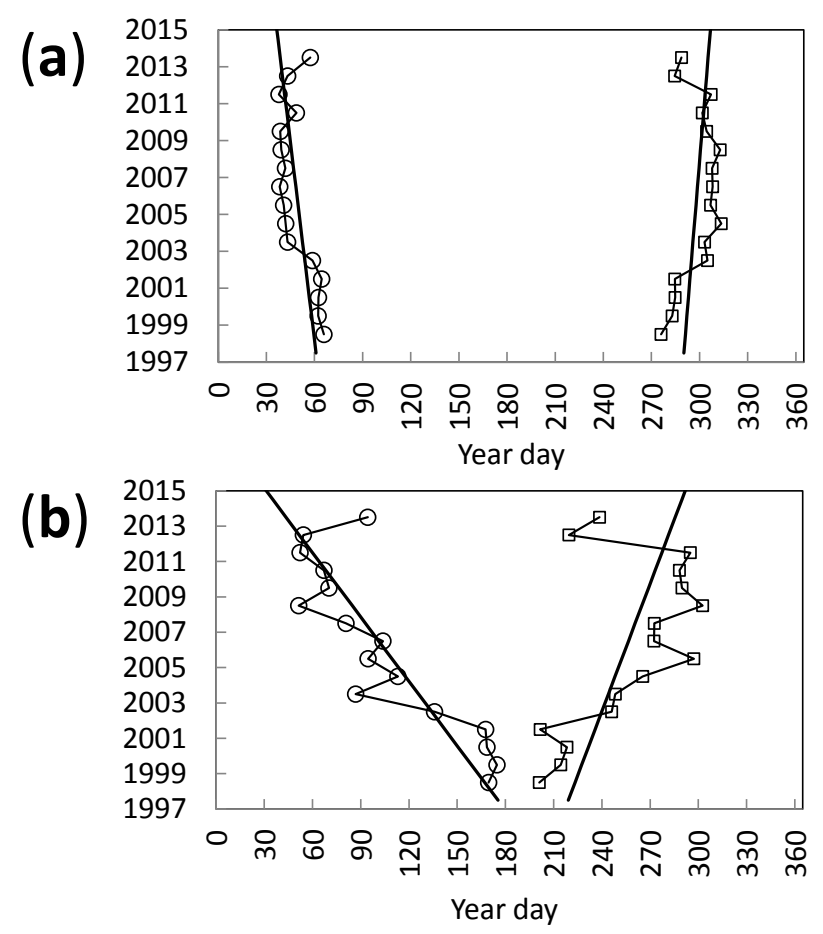

Figure 7. Temporal changes in the start and end of $\operatorname{Ked} 490=0.1 \mathrm{~m}^{-1}$ (a) and Ked490 $=0.4 \mathrm{~m}^{-1}$ (b) for the central Baltic Sea (area indicated in Fig. 1b). The circles show the first day of the year (DFKED) and the squares show the last day of the year (DLKED) with the respective value of Ked490. The regression lines have been estimated for the time period of 1998-2013.

non-algal particles. As phytoplankton are expected to have a strong annual cycle in the open Baltic Sea, it is likely that the distinct spring increase in CHL is due to the phytoplankton spring bloom. The timing of the annual satellite-derived CHL maximum (DMCHL) averaged over central Baltic (Fig. 1b) has advanced from 1998 to 2013. However, interpreting this change is complex, as there are two main annual peaks, one due to the mainly diatom-dominated spring bloom, the other associated with the cyanobacterial summer bloom. It is notable that while in the 1980s (e.g., 1985-1989, Kahru et al., 1991) the spring bloom concentration of chlorophyll $a$ measured at sea was approximately double of that of the late summer cyanobacteria bloom (dashed line in Fig. 9a), currently the satellite-estimated CHL during the summer cyanobacteria bloom is significantly higher (solid line in Fig. 9a). A similar change in chlorophyll values around 1990, with a decrease in spring and an increase in summer, has been reported from the western Gulf of Finland (Raateoja et al., 2005). While the timing of both spring and summer blooms has become earlier, the switching of the annual maximum between those two can create large interannual fluctuations. While the summer CHL maximum in 1985-1989 occurred in late summer (August-September, year days 213-270), the current satellite estimate of the summer maximum is around
July 7 (year day 188), in the period that in 1985-1989 coincided with the summer minimum (Fig. 9a). Both an earlier start and a later end of high CHL values are detected using $3 \mathrm{mg} \mathrm{m}^{-3}$ threshold value (Fig. 9b). The duration of the annual period with CHL of at least $3 \mathrm{mg} \mathrm{m}^{-3}$ (DDCHL3) has doubled, from approximately 110 days in 1998 to approximately 220 days in 2013. This increase in the duration of high absorption of light by CHL and various associated substances is likely to have important ecological consequences. As with Ked490, the last 1-2 years deviate from the general trend.

\subsection{Frequency of cyanobacteria surface accumulations}

Cyanobacteria are a major component of the Baltic phytoplankton community with some unique features. Their ability to fix nitrogen makes them important in driving the nitrogen cycle and stimulating summer primary production (e.g., Larsson et al., 2001; Karlson et al., 2015). The propensity of the co-dominant genus Nodularia to form dense surface accumulations makes it feasible to map their distribution using satellite sensors, including some not specifically designed for ocean color applications (Kahru and Elmgren, 2014). This makes it possible to create time series that are much longer than the time series using only ocean color variables (e.g., CHL). A 36-year time series of the frequency of FCA shows a trend towards earlier occurrence as measured by the center of timing of the accumulations (Fig. 10). The estimates of the start and end of the accumulation period are less reliable when based on the older, less sensitive AVHRR sensor and are therefore given only for the second half of the study period, based on the more sensitive and reliable ocean color sensor data. The start and end of the accumulation period are closely related to the center of timing. In years when the accumulations are late (e.g., 2004), the total period of accumulations also tends to be shorter.

\section{Discussion}

We have applied a uniform set of phenological indicators to a number of variables ranging from physical drivers of the environment, such as incoming shortwave energy, seasurface temperature and winds, to ecological (Ked490, CHL) and biological (cyanobacteria) components of the Baltic Sea ecosystem. Satellite-derived variables have the advantage of providing extended areal coverage instead of a point sample, with a regular and frequent sampling that is required for estimating phenological indicators. While satellite measurements using the visible and infrared spectrum are limited by cloudy periods, the effective sampling frequency is still much higher than with shipboard monitoring. For variables with large systematic errors such as satellite-detected CHL in the Baltic Sea, the phenological indicators are preferred as they have potentially less uncertainty compared to abso- 


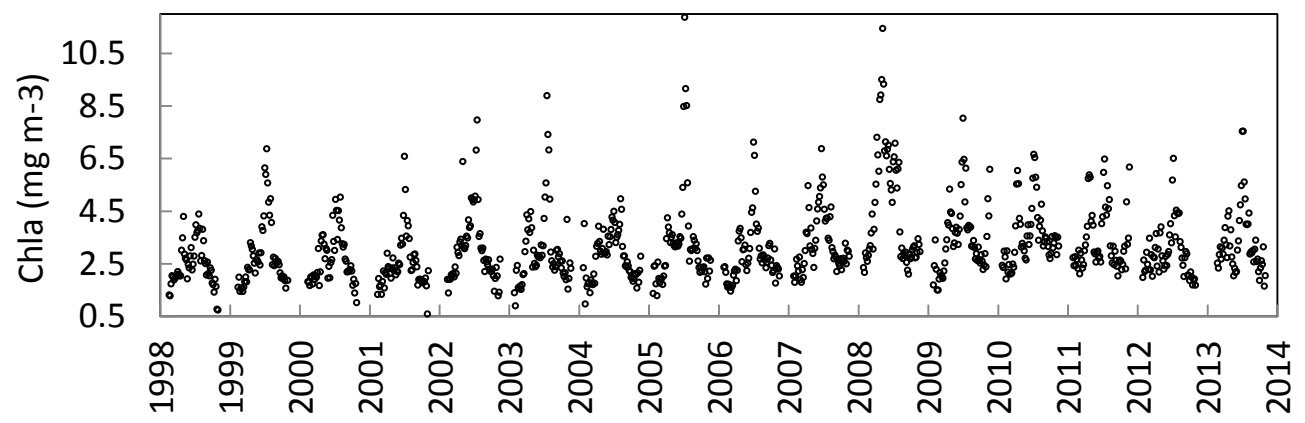

Figure 8. Time series of the 5-day mean CHL $\left(\mathrm{mg} \mathrm{m}^{-3}\right)$ in the central Baltic Sea (area indicated in Fig. 1b) derived from the ESA-CCI processing of SeaWiFS, MERIS and Aqua-MODIS satellite data (Lavender et al., 2015).

(a)

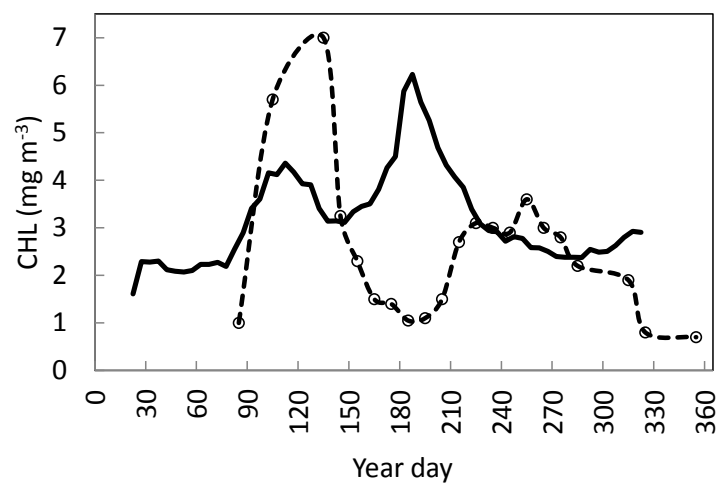

(b)

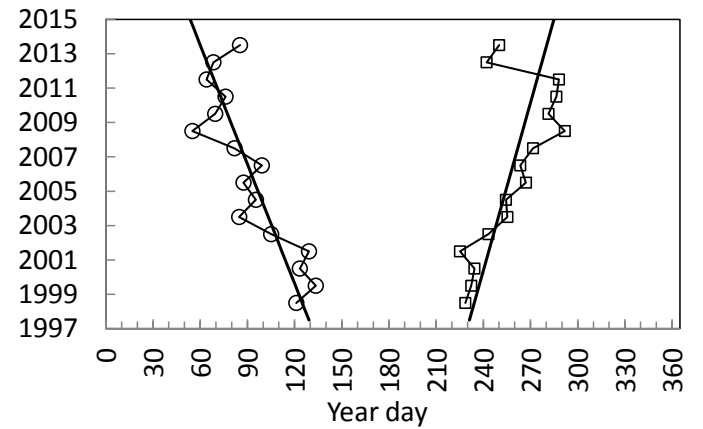

Figure 9. (a) Mean annual cycle of CHL in central Baltic Sea (area indicated in Fig. 1b) for 1997-2013 (solid line) compared with CHL measured in situ in 1985-1989 (circles, dashed line, from Kahru et al., 1991). (b) Temporal changes in the start and end of the "high chlorophyll season" (CHL $>=3 \mathrm{mg} \mathrm{m}^{-3}$ ) in the Baltic Sea. The connected markers and the respective regression lines are (from left to right): day when $\mathrm{CHL}=3.0 \mathrm{mg} \mathrm{m}^{-3}$ is reached for the first time (DFCHL3, circles) and day when CHL $=3.0 \mathrm{mg} \mathrm{m}^{-3}$ is reached for the last time (DLCHL3, squares) during the season.

lute values, particular during periods of rapid change like the phytoplankton spring bloom. However, uncertainty in timing becomes bigger during periods of slow change. The effect of missing days due to cloud cover is another factor causing errors in phenology. As we track the phenology of variables averaged over large areas (e.g., most of the Baltic Sea), the potential errors and quasi-random fluctuations are smoothed out. Systematic differences in missing data due to cloud cover (e.g., mostly southern or mostly northern areas) are another source of uncertainties in our phenological indicators and may be responsible for some of the interannual wiggles in the time series. Total uncertainties in our phenological indicators are complex and caused by errors in individual measurements, and the confounding effects of spatial and temporal compositing. However, the interannual trends in most variables are quite clear and that makes us confident that the errors are much smaller than the observed trends.

While significant trends can be detected in the absolute values of a number of variables - e.g., the increasing trends of SST, Ked490 and CHL - the phenological indicators often show more marked change and clearer trends, even when trends in the mean values are questionable or nonsignificant. For example, the time series of incoming shortwave irradiance (SIS, $\mathrm{W} \mathrm{m}^{-2}$ ) are highly regular with no apparent trends in the absolute daily values but the timing of SIS shows subtle but significant changes in seasonality, with energy input decreasing slightly in winter, but increasing during spring and summer. As a result, the cumulative sum of $30000 \mathrm{~W} \mathrm{~m}^{-2}$ was reached about 23 days earlier in 2013 than at the beginning of the time series in 1983. Over the same period, the center of timing of the summer cyanobacterial bloom (Fig. 10) became over 17 days earlier, a similarity that is likely to be more than a coincidence. A probable explanation for the reduced SIS input in winter is increased cloudiness.

The mean annual SST has increased during the last decades, in agreement with the overall warming trend. However, changes in the timing of the annual SST cycle are more drastic. As a result of the earlier warming and later cooling, the period with SST above $16^{\circ} \mathrm{C}$ has increased at a mean rate of 0.98 day year ${ }^{-1}$. Surprisingly, in contrast to the earlier warming of the sea in the spring and early summer and later cooling in the fall, the start and end of the summer temperature maximum $\left(\sim 22^{\circ} \mathrm{C}\right)$ have not changed and the duration with the highest SST has stayed the same.

Dramatic changes have occurred recently in the annual cycle of the coefficient of light attenuation (Ked490), an indi- 


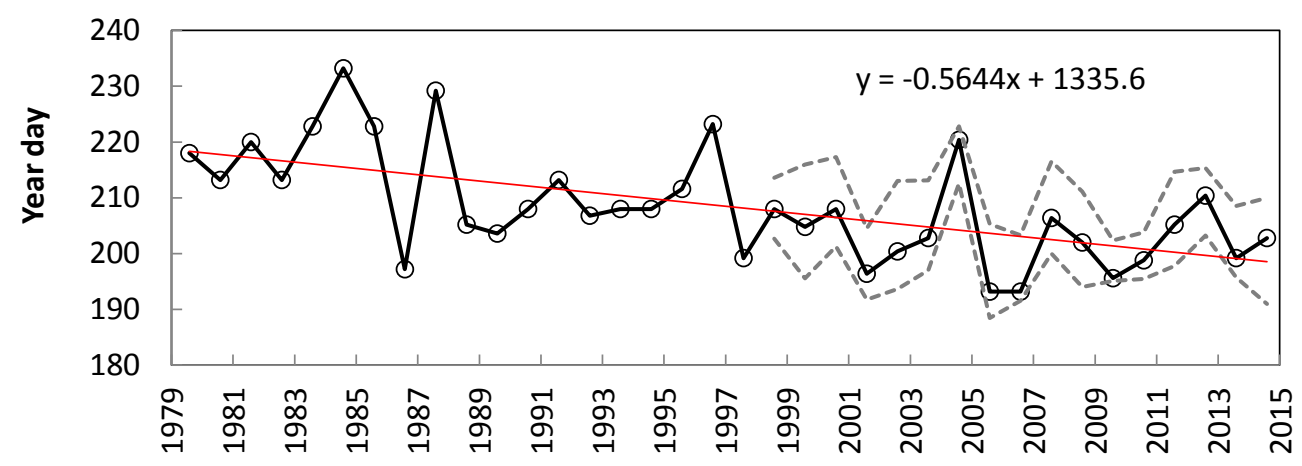

Figure 10. Temporal change in the timing of cyanobacteria accumulations for the Baltic Sea. The circles connected with a solid line show the "center of timing" (modified after Kahru and Elmgren, 2014, by adding 2014 data). The red line is the estimated linear regression for the Baltic (area in Fig. 1a). The gray dotted lines show the mean start and end of the accumulations for the whole Baltic Sea. For reference, 1 July is year day 182 (183 in leap years), year day 200 is July 19 (in leap years, July 18).

cator of water transparency. The duration of the period with elevated but intermediate Ked490 has somewhat increased but the duration of the period with high mean Ked490 (over $0.4 \mathrm{~m}^{-1}$ ) has lengthened greatly - i.e., by approximately 180 days from 1998 to 2013. Similarly, the duration of the period with high CHL (operationally defined as CHL of at least $3 \mathrm{mg} \mathrm{m}^{-3}$ ) has increased as the spring increase has advanced at a mean rate of -1.6 day year $^{-1}$ and the end of the high CHL period in the fall bloom has been delayed at the mean rate of 1.9 day year ${ }^{-1}$. These changes in the timing of high Ked490 and CHL are clearly correlated with the changes towards earlier warming and later cooling of SST, but the rate of change is faster. Since the satellite-derived time series of Ked490 and CHL are shorter and less reliable than the time series of SST, their estimated mean rates of change are also less accurate. However, it seems that the response of the biological system to climate change and eutrophication is amplified compared to the changes in the timing of the physical environment.

The changes in the timing of Ked 490 and CHL are related and reflect increased turbidity and decreased water transparency in the Baltic Sea. An obvious consequence of the increased Ked490 is that less light reaches depths below the surface. While this analysis was done for the central Baltic with small areas of benthic photosynthesis, we can assume that benthic communities in the coastal areas must also be experiencing significant reduction in light intensity due to the decreased water transparency. We can hypothesize that the increased turbidity and decreased water transparency are related to increased phytoplankton concentrations and increased bacterial production. Likely effects on the rest of the ecosystem including commercially important fisheries should be further evaluated.

The phenological indicators that we applied to a number of satellite-detected variables show significant climate-related changes in the Baltic Sea ecosystem. It appears that the biological response to climate warming is amplified, compared to the rate of change in the physical forcing (SIS and SST). As satellite-derived CHL algorithms in the Baltic Sea are inaccurate and noisy (e.g., Darecki and Stramski 2004) primarily due to the confounding influence of high concentrations of CDOM - trends in absolute values of CHL are difficult to interpret. For example, an apparently increasing trend in CHL could be influenced by increasing concentrations of CDOM or non-algal particles. However, the start of the annual increase in CHL is much more likely to reflect the increase in phytoplankton due to the known phytoplankton spring bloom and the dependence of photosynthesis on the annual cycle of light and stratification. Elevated concentrations of CDOM and non-algal particles are perhaps more likely to be partly responsible for extending the high CHL period in the fall.

Cyanobacterial blooms are a worldwide phenomenon associated with eutrophication of lakes, reservoirs and estuaries, toxic contamination of drinking water, and other undesirable effects. They cause major environmental problems in the North American Great Lakes (Stumpf et al., 2012), in lakes in China (Paerl et al., 2011) and in the Baltic Sea (Funkey et al., 2014; Kahru and Elmgren, 2014). As cyanobacterial growth in temperate zones is enhanced by higher temperatures and near-surface stratification, these blooms are expected to become more frequent as a result of climate change (Pearl and Huisman, 2008, 2009; Wiedner et al., 2007). Cyanobacterial growth typically accelerates above $12^{\circ} \mathrm{C}$ and peaks above $17^{\circ} \mathrm{C}$ (e.g., Hense et al., 2013). We can therefore assume that the earlier start of the warm-up (measured as DFSST12) and later start of cool-down (measured as DLSST12) indicate improved conditions for cyanobacteria in the Baltic Sea. By this measure, the duration of both the growth season and the "enhanced growth season" (DDSST17) have become significantly longer. The duration of the period with a mean SST of at least $16^{\circ} \mathrm{C}$ has increased, from 40 days in 1982 to 72 days in 2014 - i.e., by about 32 days (Fig. 5b), and the period with SST of at least $17^{\circ} \mathrm{C}$ (DDSST17) from 29 days 
in 1982 to 56 days in 2014 - i.e., almost doubled. Indeed, in accordance with these trends in SST, we see indications that cyanobacteria are becoming more dominant in the phytoplankton community. That dominant cyanobacterial genera in the Baltic Sea, especially Aphanizomenon and Nodularia, are buoyant may both contribute to the higher turbidity and favor them over non-buoyant phytoplankton. While in the 1980s the annual CHL maximum corresponded to the diatom spring bloom (in May in the central Baltic), it has now shifted to the cyanobacteria bloom in July, which has also advanced from its previous mean timing in August.

Even though the Baltic Sea is one of the marine areas in the world best covered by observations, the frequency of long-term sampling is insufficient for a confident detection of similar phenological indicators using measurements at sea. Instead, comparisons can be made with mathematical models simulating ecosystem dynamics over decades with high temporal resolution (e.g., Eilola et al., 2011; Hense et al., 2013; Meier et al., 2012). For instance, BALTSEM (BAltic Long-Term large Scale Eutrophication Model, Savchuk et al., 2012) produces quite similar tendencies in the Central Baltic Sea (Fig. 1b). The prolongation of the vegetative season from about 190 days in the beginning of 1970s to about 230 days in the middle of 2010s has been accompanied by a tripling of the net primary production and shift of the annual biomass maximum from spring to summer. Due to earlier warming and delayed cooling, the duration of the period with simulated surface water temperature exceeding $14^{\circ} \mathrm{C}$, the assumed threshold for initiation of nitrogen fixation by cyanobacteria in the model, has increased from about 75 days in 1982 to about 110 days in 2014 - i.e., by 35 days (see Fig. 5b). The center of timing of simulated cyanobacteria development has become 17 days earlier (see Fig. 10).

\section{Conclusions}

Phenological indicators are sensitive in detecting environmental changes that are often hardly detectable using absolute values of the respective environmental variables. Moreover, these indicators - e.g., the duration of the growth season - may have special ecological significance. Using these phenological indicators we show significant and in some cases drastic changes in the seasonality of the Baltic Sea. These changes are evident in multiple variables from purely physical to ecological to biological. For several ecologically important variables (Ked490, CHL) the length of the annual period of high values has increased by a factor of 2 or more during the last 2 decades. The analyses reported above are based on satellite data, meaning that the phenological analyses of this type can be made for most areas of the globe and not only for comparatively data-rich areas like the Baltic Sea.

Acknowledgements. Financial support was provided by the Swedish Research Council Formas and Stockholm University's
Baltic Ecosystem Adaptive Management Program. During the writing of this paper M. Kahru was supported by HanseWissenschaftskolleg (Delmenhorst, Germany). The authors thank Uwe Pfeifroth, Jörg Trentmann, and Christine Träger-Chatterjee for help in accessing SIS data, H. W. Paerl, R. P. Stumpf and C. Rolff for comments on the manuscript, and CM SAF, NASA Ocean Color Processing Group and ESA OC-CCI group for satellite data.

Edited by: K. G. Schulz

\section{References}

Atlas, R., Ardizzone, J., and Homan, R. N.: Application of satellite surface wind data to ocean wind analysis, Proc. SPIE, 7087B, doi:10.1117/12.795371, 2008.

Attila, J., Koponen, S., Kallio, K., Lindfors, A., Kaitala, S., and Ylöstalo, P.: MERIS Case II water processor comparison on coastal sites of the northern Baltic Sea, Remote Sens. Environ., 128, 138-149, 2013.

Belkin, I. M.: Rapid warming of large marine ecosystems, Prog. Oceanogr., 81, 207-213, 2009.

Beyer, H. G., Costanzo, C., and Heinemann, D.: Modifications of the Heliosat procedure for irradiance estimates from satellite images, Sol. Energy, 56, 207-212, 1996.

Cano, D., Monget, J. M., Albuisson, M., Guillard, H., Regas, N., and Wald, L.: A method for the determination of the global solarradiation from meteorological satellite data, Sol. Energy, 37, 25 31-39, 1986.

Casey, K. S., Brandon, T. B., Cornillon, P., and Evans, R.: The past, present and future of the AVHRR Pathfinder SST program, in: Oceanography from Space: Revisited, edited by: Barale, V., Gower, J. F. R., and Alberotanza, L., Springer, New York, 323341, doi:10.1111/gcb.13059, 2010.

Cloern, J. E., Abreu, P. C., Carstensen, J., Chauvaud, L., Elmgren, R., Grall, J., Greening, H., Johansson, J. O. R., Kahru, M., Sherwood, E. T., Xie, J., and Yin, K.: Human activities and climate variability drive fast-paced change across the world's estuarine-coastal ecosystems, Glob. Change Biol., 22, 513-529, doi:10.1111/gcb.13059, 2016.

Darecki, M. and Stramski, D.: An evaluation of MODIS and SeaWiFS bio-optical algorithms in the Baltic Sea, Remote Sens. Environ., 89, 326-350, 2004.

Eilola, K., Gustafsson, B. G., Kuznetsov, I., Meier, H. E. M., Neumann, T., and Savchuk, O. P.: Evaluation of biogeochemical cycles in an ensemble of three state-of-the-art numerical models of the Baltic Sea, J. Marine Syst., 88, 267-284, 2011.

Elmgren, R.: Man's impact on the ecosystem of the Baltic Sea: energy flows today and at the turn of the century, Ambio, 18, 326332, 1989.

Elmgren, R.: Understanding human impact on the Baltic ecosystem: changing views in recent decades, Ambio, 30, 222-231, 2001.

Funkey, C. P., Conley, D. J., Reuss, N. S., Humborg, C., Jilbert, T., and Slomp, C. P.: Hypoxia sustains cyanobacteria blooms in the Baltic Sea, Environ. Sci. Technol., 48, 2598-2602, 2014.

Hense, I., Meier, H. E. M., and Sonntag, S.: Projected climate change impact on Baltic Sea cyanobacteria, Climatic Change, 119, 391-406, 2013. 
Kahru, M. and Elmgren, R.: Multidecadal time series of satellitedetected accumulations of cyanobacteria in the Baltic Sea, Biogeosciences, 11, 3619-3633, doi:10.5194/bg-11-3619-2014, 2014.

Kahru, M., Kaasik, E., and Leeben, A.: Annual cycle of particle size fractions and phytoplankton biomass in the northern Baltic proper, Mar. Ecol.-Prog. Ser., 69, 117-124, 1991.

Kahru, M., Savchuk, O. P., and Elmgren, R.: Satellite measurements of cyanobacterial bloom frequency in the Baltic Sea: interannual and spatial variability, Mar. Ecol.-Prog. Ser., 343, 15-23, 2007.

Kahru, M., Brotas, V., Manzano-Sarabia, M., and Mitchell, B. G.: Are phytoplankton blooms occurring earlier in the Arctic?, Glob. Change Biol., 115, 1733-1739, doi:10.1111/j.13652486.2010.02312.x, 2010.

Karlson, A. M. L., Duberg, J., Motwani, N. H., Hogfors, H., Ploug, H., Svedén, J. B., Garbaras, A., Sundelin, B., Hajdu, S., Larsson, U., Elmgren, R., and Gorokhova, E.: Nitrogen fixation by cyanobacteria stimulates production in Baltic food-webs, Ambio, 44, 413-426, 2015.

Kratzer, S., Hakansson, B., and Sahlin, C.: Assessing Secchi and photic zone depth in the Baltic Sea from satellite data, Ambio, 32, 577-585, 2003.

Larsson, U., Hajdu, S., Walve, J., and Elmgren, R.: Baltic Sea nitrogen fixation estimated from the summer increase in upper mixed layer total nitrogen, Limnol. Oceanogr., 46, 811-820, 2001.

Lavender, S., Jackson, T., and Sathyendranath, S.: The Ocean Colour Climate Change Initiative, Ocean Chall., 21, 29-31, 2015.

Lee, Z., Du, K., and Arnone, R.: A model for the diuse attenuation coecient of downwelling irradiance, J. Geophys. Res., 110, C02016, doi:10.1029/2004JC002275, 2005.

Meier, H. E. M., Müller-Karulis, B., Andersson, H. C., Dieterich, C., Eilola, K., Gustafsson, B. G., Höglund, A., Hordoir, R., Kuznetsov, I., Neumann, T., Ranjbar, Z., Savchuk, O. P., and Schimanke, S.: Impact of climate change on ecological quality indicators and biogeochemical fluxes in the Baltic Sea: a multimodel ensemble study, Ambio, 41, 558-573, 2012.

Mueller, R., Matsoukas, C., Gratzki, A., Behr, H., and Hollmann, R.: The CM-SAF operational scheme for the satellite based retrieval of solar surface irradiance - A LUT based eigenvector hybrid approach, Remote Sens. Environ., 113, 1012-1024, 2009.
Müller, R., Pfeifroth, U., Träger-Chatterjee, C., Cremer, R., Trentmann, J., and Hollmann, R.: Surface Solar Radiation Data Set Heliosat (SARAH), 1 Edn., Satellite Application Facility on Climate Monitoring, doi:10.5676/EUM_SAF_CM/SARAH/V001, 2015.

O’Reilly, J., Maritorena, S., Mitchell, B. G., Siegel, D., Carder, K. L., Garver, S., Kahru, M., and McClain, C.: Ocean color chlorophyll algorithms for SeaWiFS, J. Geophys. Res., 103, 2493724953, 1998.

Paerl, H. W. and Huisman, J.: Climate - Blooms like it hot, Science, 320, 57-58, 2008.

Paerl, H. W. and Huisman, J.: Climate change: a catalyst for global expansion of harmful cyanobacterial blooms, Environ. Microbiol., 1, 27-37, 2009.

Paerl, H. W., Xu, H., McCarthy, M. J., Zhu, G., Quin, B., Yi, L., and Gardner, W. S.: Controlling harmful cyanobacterial blooms in a hyper-eutrophic lake (Lake Taihu, China): the need for a dual nutrient (N and P) management strategy, Water Res., 45, 19731983, 2011.

Raateoja, M., Seppälä, J., Kuosa, H., and Myrberg, K.: Recent changes in trophic state of the Baltic Sea along SW coast of Finland, Ambio, 34, 188-191, 2005.

Salmi, T., Määttä, A., Anttila, P., Ruoho-Airola, T., and Amnell, T.: Detecting trends of annual values of atmospheric pollutants by the Mann-Kendall test and Sen's slope estimates - the Excel template application MAKESENS, Publications on air quality, 31, ISBN 951-697-563-1, 35 pp., 2002.

Savchuk, O. P., Gustafsson, B. G., and Müller-Karulis, B.: BALTSEM - a marine model for decision support within the Baltic Sea Region, Baltic Nest Institute Techn. Rep. Ser., 7, 55 pp., 2012.

Sen, P.K.: Estimates of the regression coefficient based on Kendall's tau, J. American Statist. Assoc., 63, 1379-1389, 1968.

Stumpf, R. P., Wynne, T. T., Baker, D. B., and Fahnenstiel, G. L.: Interannual variability of cyanobacterial blooms in Lake Erie, PLoS One, 8, e42444, doi:10.1371/journal.pone.0042444, 2012.

Wiedner, C., Rücker, J., Brüggemann, R., and Nixdorf, B. S.: Climate change affects timing and size of populations of an invasive cyanobacterium in temperate regions, Oecologia, 152, 473-484, 2007. 